\title{
Perioperative Ketamine Infusion is Effective in Reversing Opioid-Induced HyPERALgesia
}

\author{
Xiaomin Liang, MD', Kenneth D. Candido, MD ${ }^{1,2}$, and Nebojsa Nick Knezevic, MD, PhD ${ }^{1,2}$
}

Opioid-induced hyperalgesia (OIH) is a condition of nociceptive sensitization caused by exposure to opioids, which is characterized by a paradoxical response whereby patients receiving opioids for the treatment of pain actually become more sensitive to pain as a direct result of opioid therapy. There is increasing evidence showing $\mathrm{OlH}$ presents a clinical challenge in acute, chronic, and cancer pain settings. Both clinical and animal studies have shown that glutamate N-methyl-Daspartate (NMDA) receptors may play a key role in OIH and pre-application of ketamine, an NMDA receptor antagonist, or co-administration of ketamine and opioids, can prevent $\mathrm{OIH}$. However, no reports have shown if ketamine can reverse OIH once it occurs.

We present a case of a 56-year-old male with past medical history of DM-2 with severe peripheral neuropathy, recurrent osteomyelitis of the left foot, hypertension, dyslipidemia, chronic neck and right arm pain due to cervical spondylosis, status post four times of cervical discectomy and fusion surgeries for cervical radiculopathy. He was on high doses of opioids (MS Contin 60 $\mathrm{mg}$ po $\mathrm{q} 8$ hour and hydrocodone/acetaminophen $10 / 325$ prn- up to 4 times daily) for approximately
10 years. He underwent left below knee amputation due to uncontrolled osteomyelitis. The patient had worsening stump pain with increasing dose of opioids and phantom pain on post-operative day 1 , and he developed $\mathrm{OIH}$, diagnosed as escalating pain reports with every opioid dose increase. A ketamine infusion (loading dose $10 \mathrm{mg}$ IV bolus, then $20 \mathrm{mg} /$ hour IV infusion) was used after total cessation of opioid use for postoperative analgesia for 3 consecutive days and the patient recovered from his obvious $\mathrm{OlH}$, with his stump pain and phantom pain well-controlled by opioid administration on post-operative day 5 .

In our case, blockage of NMDA receptors by ketamine might quickly restore the balance between opioid-dependent analgesic systems and NMDA-dependent pronociceptive systems by deactivation of the latter, which may help the patient recover from $\mathrm{OlH}$ rapidly. While it is possible that ketamine may help facilitate patients' recovery from OIH in addition to its ability to prevent $\mathrm{OIH}$, this clinical observation has to be tested in future prospective studies.

Key words: Ketamin, opioid-induced hyperalgesia
From: ${ }^{~}$ Department of Anesthesiology, Advocate Illinois Masonic Medical Center, Chicago, IL; ${ }^{2}$ Department of Anesthesiology, University of Illinois, Chicago, IL

Author for Correspondence: Kenneth D. Candido, MD Address Correspondence: Department of Anesthesiology, Advocate Illinois Masonic Medical Center, 836 W. Wellington Ave. Suite 4815, Chicago, IL 60657.

Email: kdcandido1@gmail.com
Opioid-induced hyperalgesia $(\mathrm{OIH})$ is a condition of nociceptive sensitization caused by exposure to opioids, which is characterized by a paradoxical response whereby patients receiving opioids for the treatment of pain actually become more sensitive to pain as a direct result of opioid therapy (1). The type of pain experienced in OlH might be either the same as or different than the original underlying pain (1). OIH can occur in different settings characterized by the opioid dose administered (high doses vs. low doses) and the pattern of administration (long term use vs. 
short term use) (2). Despite the fact that there has been discussion about clinical importance of $\mathrm{OIH}$, it is becoming an important challenging factor in acute, chronic, and cancer pain (3). The mechanism underlying $\mathrm{OlH}$ is not clear. However, both clinical and animal studies have pointed out that the glutamate $\mathrm{N}$-methylD-aspartate (NMDA) receptor, known to play a key role in central sensitization, may be involved in $\mathrm{OlH}$ $(3,4)$. Experimental animal studies as well as clinical data have shown that NMDA receptor antagonists such as ketamine inhibit central sensitization and prevent $\mathrm{OlH}$ (3-7). Although pre-application of ketamine or co-administration of ketamine and opioids demonstrated the benefits of preventing $\mathrm{OIH}$ in some studies (3-7), to date there have been no reports showing that ketamine can reverse $\mathrm{OlH}$ or facilitate patients' recovery from $\mathrm{OlH}$ once it occurs.

In this report, we present a case of successful use of a ketamine infusion over 3 days in reversing acute development of $\mathrm{OIH}$ that evolved rapidly following surgery in an opioid-tolerant patient, wherein we successfully used ketamine to reverse the $\mathrm{OIH}$ and make opioid therapy effective again.

\section{CASE DESCRIPTION}

The patient gave written permission for the authors to publish the report.

A 56-year-old male with a past medical history of DM-2 with severe peripheral neuropathy, recurrent osteomyelitis of the left foot, hypertension, dyslipidemia, and chronic neck and right arm pain due to cervical spondylosis, underwent four cervical discectomy and fusion surgeries for cervical radiculopathy over an 18 month period. He visited our pain clinic regularly and was on high doses of opioids (MS Contin $60 \mathrm{mg}$ po q8 hour and hydrocodone/APAP, 10/325 prn-up to 4 times daily) for approximately 10 years. He underwent left below the knee amputation due to severe diabetic foot neuropathy and toe necrosis associated with chronic, unresolving osteomyelitis. The surgery lasted 108 minutes and was performed under spinal anesthesia ( $0.5 \%$ bupivacaine isobaric $2 \mathrm{~mL}+$ fentanyl $25 \mathrm{mcg}$ intrathecal), combined with monitored anesthesia care (midazolam $15 \mathrm{mg}$ in divided doses, ketamine $70 \mathrm{mg}$ iv and Propofol IV infusion at $25 \mathrm{mg} / \mathrm{kg} / \mathrm{hour}$ ).

On post-operative day 1 , he complained of severe intolerable left leg stump pain, that was throbbing and sharp, worse with movement, graded 10 on 0-10 numeric rating scale (NRS). The patient also had a phantom limb pain into the amputated foot and ankle while using escalating doses of IV PCA hydromorphone and later morphine when hydromorphone escalating doses was noted to worsen pain. At each dose increase the pain was accentuated as the opioid dose was increased.

The total dose of opioid administered during the first 24 hours was hydromorphone PCA $30 \mathrm{mg} \mathrm{IV}$, hydromorphone $12 \mathrm{mg}$ po, morphine PCA $30 \mathrm{mg} \mathrm{IV}$, fentanyl $500 \mathrm{mcg}$ IV and finally, a fentanyl patch at $12 \mathrm{mcg} /$ hour (total 24 hour dose $=288 \mathrm{mcg}$ ), which translates to an equivalent dose of oral morphine of $650 \mathrm{mg}$ with the reduction for incomplete cross tolerance taken as $30 \%$ (Table 1 ).

On post-operative day 2, opioids were discontinued due to lack of efficacy despite increasing dosing, and ketamine (loading dose $10 \mathrm{mg} \mathrm{IV}$, followed by an infusion rate $20 \mathrm{mg} / 70 \mathrm{~kg} / \mathrm{hr}$ ) was used in place of opioid infusions for 3 consecutive days.

The stump pain and phantom pain were improved immediately with a 3/10 NRS for stump pain and much reduced phantom pain $(N R S=1 / 10)$ on day 3. On post-operative day 5 (72 hours after starting use of ketamine), the infusion rate of ketamine was decreased by $5 \mathrm{mg} / 3-4$ hour until it was discontinued. His previously used analgesia using fentanyl patch was then re-started at $12 \mathrm{mcg} / \mathrm{hour} / 72$ hours and was increased by $25 \mathrm{mcg}$ every 3-5 days until a dose of $75 \mathrm{mcg} /$ hour was attained. On post-operative day 7 , he felt moderate stump pain (NRS $=4 / 10)$ but had no phantom pain. On day 20, he was discharged home from with fentanyl patch $75 \mathrm{mcg} / 72$ hours with mild stump pain (NRS $=1-2 / 10)$ but without any phantom limb pain whatsoever. On day 29 , the patient was re-evaluated at our pain clinic; his fentanyl patch had been discontinued due to intractable pruritis, and he was on MS Contin $60 \mathrm{mg}$ q8 hours and morphine sulfate $15 \mathrm{mg}$ q4 hours PRN with intermittent burning sensation at the stump of the amputated leg and without complaints of phantom pain.

\section{DISCUSSION}

It is well known that hyperalgesia can occur after prolonged exposure to opioids and this condition 
Ketamine Reversing Opioid-induced Hyperalgesia

has been designated as opioid-induced hyperalgesia $(\mathrm{OIH})$. It should be noted that $\mathrm{OlH}$ is not a common occurrence in most instances; however, when it does occur it maybe unrelated to the initial starting dose of opioids used to manage acute pain, regardless of level of tolerance development due to chronic opioid dosing. The hallmark however, is consistent worsening of the pain with increased dosing of opioids. Opioids have been used to control pain following amputation (8). On day 1 post-surgery in the present case, the patient suffered both severe stump pain and phantom pain, which could not be controlled by escalating doses of opioids, and indeed, both of which reportedly worsened at every dose escalation. Although tolerance can also follow prolonged usage of opioids (9), we consider that this increasing pain with increasing opioid dosing represented hyperalgesia instead of tolerance based upon the rapid pain escalation commensurate with every dose increase, which is not characteristic of the more gradual process of habituation and tolerance. With development of tolerance the efficacy of opioids decreases, whereas the pain can be relieved by increased opioids, which is different from hyperalgesia $(\mathrm{OIH})$ in which increasing opioid doses aggravate pain $(1,9)$.

Phantom pain is defined as pain wherein patients feel pain in a body part that is no longer present following amputation (10). Fifty percent of patients suffer from phantom pain within the first 24 hours following amputation and this pain is generally opioid and adjuvant analgesic medication resistant (10). In this present case, we discontinued all opioids and instead used a ketamine infusion from days 2 to 4 post-operation resulting in the patient becoming in a state of profound relaxation. Concomitantly, both stump pain and phantom pain were well controlled.

Ketamine infusion has been used in chronic pain states and for providing post-operative analgesia $(11,12)$. In a double-blind prospective randomized clinical trial (5) performed on 45 patients undergoing fusion for treating lumbar spondylolisthesis, ketamine infusion $(0.5 \mathrm{mg} / \mathrm{kg} / \mathrm{h})$ was shown to be more efficient in postoperative pain reduction during the first 24 hours compared with routine morphine administration (5 mg IV) although both were effective methods of pain control. In another randomized controlled study involving 160 pregnant women undergoing cesarean section with spinal anesthesia, five minutes after
Table 1. Opioid use during the first 24 hours, with dose converted to oral morphine equivalents, with a reduction for incomplete cross tolerance taken as $30 \%$ (based on "Equivalent opioid calculator http://www.clincalc.com/ Opioids/ accessed October 5, 2015.)

\begin{tabular}{|l|c|c|c|}
\hline Opioid & Route & Dose & $\begin{array}{c}\text { Equivalent } \\
\text { dose of oral } \\
\text { morphine }\end{array}$ \\
\hline Hydromorphone & IV PCA & $30 \mathrm{mg}$ & $420 \mathrm{mg}$ \\
\hline Hydromorphone & Oral & $12 \mathrm{mg}$ & $34 \mathrm{mg}$ \\
\hline Morphine & IV PCA & $30 \mathrm{mg}$ & $75 \mathrm{mg}$ \\
\hline Fentanyl & IV & $0.5 \mathrm{mg}$ & $105 \mathrm{mg}$ \\
\hline Fentanyl & Transdermal & $12 \mathrm{mcg} / \mathrm{h}$ & $28.8 \mathrm{mg}$ \\
\hline Total & & & $662.8 \mathrm{mg}$ \\
\hline
\end{tabular}

delivery, subjects receiving $0.25 \mathrm{mg} / \mathrm{kg}$ intravenous ketamine via bolus doses significantly reduced the requirement for analgesics and had fewer side effects caused by opioids, compared with those in control group receiving normal saline solution after delivery (13). Ketamine has also been successfully used in phantom pain (14-16) although a recent case report demonstrated lack of efficacy when ketamine is used for this purpose (17). In a randomized, double-blind and crossover study of twenty patients, ketamine (0.4 $\mathrm{mg} / \mathrm{kg}, \mathrm{IV}$ ), but not calcitonin, was shown to reduce phantom limb pain (14), which was supported by a double-blind saline-controlled study in which 11 patients had decreased stumped and phantom limb pain scores as a response to ketamine $(0.1 \mathrm{mg} / \mathrm{kg} / 5$ min IV bolus, followed by an infusion rate of $7 \mu \mathrm{g} / \mathrm{kg} /$ min) (16). Recently ketamine has been found to have antidepressant effects, which are possibly related to the selective blockade of NMDA receptor-associated ion-channels, resulting in increased glutamate release $(18,19)$. Following a single low-dose ketamine infusion $(0.5 \mathrm{mg} / \mathrm{kg}$ over $40 \mathrm{~min})$ improvement in mood reached a maximum within 72 hours (19). Since the loss of a limb may have a substantial psychological impact and since depression is a significant predicting factor for phantom pain (10), ketamine's antidepressant effect might contribute to the patient's relief from phantom pain.

In the present case, on day 5 post-operatively, we stopped using ketamine and changed back to opioid analgesics again as a prelude to preparing the patient 
for discharge, and found that, unlike the situation on day 1 , both stump pain and phantom pain could be well-controlled until the patient was finally discharged on day 20 after surgery. We believe that the subsequent and ultimate relief of pain in the present case by opioid use is due to the patient's recovery from $\mathrm{OIH}$. Until we addressed the $\mathrm{OlH}$, there was zero likelihood of addressing the acute pain related to the amputation, or that due to a phantom limb syndrome.

In rats, the hyperalgesia induced by high doses of fentanyl can last up to 10 days (20). Based on our previous experience, once OlH occurs, normally it takes approximately several weeks to a few months to suppress it once opioids are discontinued. llkjaer et al. reported that hyperalgesia proximal to the wound site was found to be present 3 months after surgery in patients recovering from abdominal hysterectomy (21). However, in our case, the patient recovered from OIH within 3 days when ketamine was substituted for opioids. Although the neurobiology of $\mathrm{OlH}$ is complex, activation of central glutaminergic pathways, (mainly via NMDA receptors), has been regarded as a key mechanism underlying analgesia $(1,9)$. In rats, Mao et al $(22,23)$ found that an increase in responsiveness of the glutamate NMDA receptor contributes to the development of $\mathrm{OlH}$ as the NMDA antagonist MK-801 prevented it from occurring. This result is also supported by an additional two animal studies in which

\section{REFERENCES}

1. Lee M, Silverman SM, Hanson H, Patel VB, Manchikanti L. A comprehensive review of opioid-induced hyperalgesia. Pain Physician 2011; 14:145-61.

2. Angst MS, Clark JD. Opioid-induced hyperalgesia: A qualitative systematic review. Anesthesiology 2006; 104:570-587.

3. Colvin LA, Fallon MT. Opioid-induced hyperalgesia: A clinical challenge. Br J Anaesth 2010; 104:125-127.

4. Joly V, Richebe P, Guignard B, Fletcher D, Maurette P, Sessler DI, Chauvin M. Remifentanil-induced postoperative hyperalgesia and its prevention with small-dose ketamine. Anesthesiology 2005; 103:147-155.

5. Koppert W, Sittl R, Scheuber K, Alsheimer M, Schelmez M, Schuttler J. Differential modulation of remifentanil-induced analgesia an postinfusion hyperalgesia by S-ketamine and clonidine in human. Anesthesiology 2003; 99:152-159.

6. Celerier E, Rivat C, Jun Y, Laulin JP, Larcher A, Reynier P, Simonnt $\mathrm{G}$. Long-lasting hyperalgesia induced by fentanyl in rats: Preventive effect of ketamine. Anesthesiology 2000; 92:465472.

7. Minville V, Fourcade O, Girolami JP, Tack I. Opioid-induced hy- ketamine, a clinically-used NMDA receptor antagonist (20), clearly reduced fentanyl or morphine-induced hyperalgesia $(7,20)$. Célèrier et al $(24)$ proposed a neuroadaptative model in which stability between opioid-dependent analgesic systems (pain inhibitory) and NMDA-dependent pronociceptive systems (pain excitatory) could be broken by repeated opioid administrations thus increasing the sensitivity and leading to the hyperalgesic state. Similar to animal studies, a human clinical study has also shown that OIH did not occur when high dose of remifentanil $(0.4 \mu \mathrm{g} / \mathrm{kg} /$ $\mathrm{min}$ ) was co-applied with $0.5 \mathrm{mg} / \mathrm{kg}$ ketamine while remifentanil alone did produce $\mathrm{OIH}$ (4). This was supported by another clinical study where, when given in combination for $30 \mathrm{~min}$, S-ketamine $(5 \mu \mathrm{g} / \mathrm{kg} / \mathrm{min})$ abolished remifentanil $(0.1 \mu \mathrm{g} / \mathrm{kg} / \mathrm{min})$-induced $\mathrm{OlH}$ (5). However, no studies have reported demonstrating whether or not ketamine infusion used as an orphan drug to manage postoperative pain can facilitate patients' recovery from $\mathrm{OIH}$. In our case, blockage of glutamate NMDA receptors by ketamine might quickly restore the balance between opioid-dependent analgesic systems and NMDA-dependent pronociceptive systems by deactivation of the latter, which may help the patient recover from OlH rapidly. While it is possible that ketamine can facilitate recovery from $\mathrm{OlH}$, the clinical observations made in this case report need to be tested in future prospective studies.

peralgesia in a mice model of orthopaedic pain: Preventive effect of ketamine. Br J Anesth 2010; 104:231-238.

8. Wu CL, Agrawal S, Tella PK, Klick B, Clark MR, Haythornthwaite JA, Max MB, Raja SN. Morphine versus mexiletine for treatment of postamputation pain: A randomized, placebo-controlled, crossover trial. Anesthesiology 2008; 109:289-296.

9. Lee HJ, Yeomans DC. Opioid induced hyperalgesia in anesthetic settings. Korean J Anesthesiol 2014; 67:299-304.

10. Wolff A, Vanduyhoven E, Vankleef M, Huygen F, Pope JE, Mekhail N. Phantom Pain. Pain Pract 2011; 11:403-413.

11. Abrishamkar S, Eshraghi N, Feizi A, Talakoub R, Rafiei A, Rahmani P. Analgesic effects of ketamine infusion on postoperative pain after fusion and instrumentation of the lumbar spine: A prospective randomized clinical trial. Med Arh 2012; 66:107-110.

12. Ben-Ari A, Lewis MC, Davidson E. Chronic administration of ketamine for analgesia. J Pain Palliat Care Pharmacother 2007; 21:7-14.

13. Rahmanian M, Leysi M, Hmmati AA, Mirmohammadkhani M. The effect of low-dose intravenous ketamine on postoperative pain following cesarean section with spinal anesthesia: A ran- 
Ketamine Reversing Opioid-induced Hyperalgesia

domized clinical trial. Oman Med J 2015; 30:11-16.

14. Eichenberger U, Neff F, Sveticic G, Bjorgo S, Petersen-Felix $S$, Arendt-Nielsen L, Curatolo M. Chronic phantom limb pain: The effects of calcitonin, ketamine, and their combination on pain and sensory thresholds. Anesth Analg 2008; 106:1265-1273.

15. Stannard CF, Porter GE. Ketamine hydrochloride in the treatment of phantom limb pain. Pain 1993; 54:227-230.

16. Nikolajsen L, Hansen CL, Nielsen J, Keller J, Arebdet-Nielsen L, Jensen TS. The effect of ketamine on phantom pain: A central neuropathic disorder maintained by peripheral input. Pain 1996; 67:69-77.

17. Sakai T, Sumikawa K. Phantom limb pain exacerbated by intravenous ketamine. J Anesth 2014; 28:643.

18. Dutta A, McKie S, Deakin J. Ketamine and other potential glutamate antidepressants. Psychiatry Res 2015; 225: 1-13.

19. Berman RM, Cappiello A, Oren DA, Heninger GR, Charney DS, Kreystal JH. Antidepressant effects of ketamine in depressed patients. Bio Psychiatry 2000; 47:351-354.

20. Rivat C, Laulin JP, Corcuff JB, Celerier E, Pain L, Simonnet G.
Fentanyl enhancement of carrageenan-induced long-lasting hyperalgesia in rats: Prevention by the N-methyl-D-aspartate receptor antagonist ketamine. Anesthesiology 2002; 96:381-391.

21. Ilkjaer S, Bach LF, Nielsen PA, Wernberg M, Dahl JB. Effect of preoperative oral dextromethorphan on immediate and late postoperative pain and hyperalgesia after total abdominal hysterectomy. Pain 2000; 86:19-24.

22. Mao J, Price DD, Mayer DJ. Thermal hyperalgesia in association with the development of morphine tolerance in rats: Roles of excitatory amino acid receptorand protein kinase C. J Neurosci 1994; 14:2301-2312.

23. Mao J, Price DD, Mayer DJ. Mechanisms of hyperalgesia and morphine tolerance: A current view of their possible interactions. Pain 1995; 62:259-274.

24. Celerier E, Laulin JP, Corcuff JB, Le Moal M, Simonnet G. Progressive enhancement of delayed hyperalgesia induced by repeated heroin administration: A sensitization process. J Neurosci $2001 ;$ 21:4074-4080.
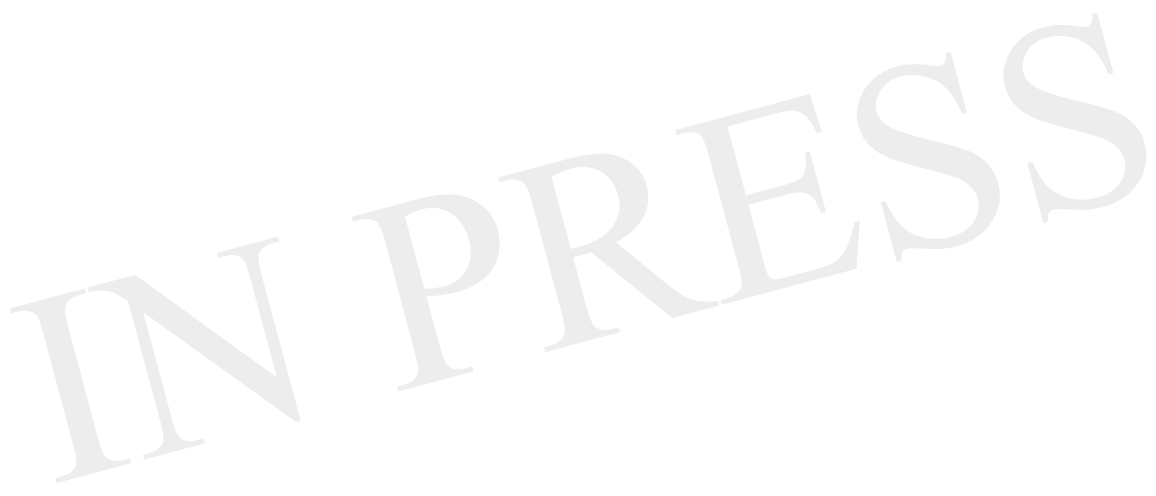
